\title{
Factors associated with surgical morbidity of primary debulking in epithelial ovarian cancer
}

\author{
Emre Günakan, MD ${ }^{1,{ }^{*}}$, Yusuf Aytaç Tohma, MD², Mehmet Tunç, MD ${ }^{1}$, Hüseyin Akıllı, MD², Hanifi Şahin, MD², \\ Ali Ayhan, MD² \\ Department of Obstetrics and Gynecology, ${ }^{1}$ Keçioren Training and Research Hospital, University of Medical Sciences, ${ }^{2}$ Baskent University School of \\ Medicine, Ankara, Turkey
}

\section{Objective}

Epithelial ovarian cancer (EOC) requires an aggressive surgical approach. The important part of literature on ovarian cancer surgery emphasize residual tumor and survival analyses. Morbidity issue keeps in background. Therefore, we aimed to report on morbidity of cytoreductive surgery for EOC in this study.

\section{Methods}

EOC patients who underwent primary debulking were evaluated. Intraoperative and postoperative complications that occurred within 30 days after the surgery and factors that affect morbidity were considered.

\section{Results}

The study involved 359 patients. Forty-six intraoperative complications occurred in $42(11.6 \%)$ patients. Advanced stage and cancer antigen level of 125 were independently and significantly associated with operative complications (hazard ratio $[\mathrm{HR}], 1.66 ; 95 \%$ confidence interval $[\mathrm{Cl}], 1.01-2,73 ; P=0.044$, and $\mathrm{HR}, 1.47 ; 95 \% \mathrm{Cl}, 1.05-2.06 ; P=0.025$, respectively). The need for intensive care unit admission was significantly higher in patients with intraoperative complications ( $28.6 \%$ vs. $8.8 \%, P=0.001)$. Intraoperative and postoperative complication rates were significantly higher in extended surgery than in standard surgery ( $18.9 \%$ vs. $8.5 \%, P=0.005$ and $38.7 \%$ vs. $10.9 \%, P<0.001$, respectively). Intraoperative and postoperative transfusion need, hospital stay duration, and chemotherapy start day were also significantly higher in extended surgery than in standard surgery. Hundred postoperative complications occurred in 70 patients. Age, extended surgery, presence of ascites, and presence of operative complications were independently and significantly associated with postoperative complications.

\section{Conclusion}

Morbidity of extensive surgical approach should be kept in mind in ovarian cancer surgery aimed at leaving no residual tumor. Patient-based management with an appropriate preoperative evaluation may avoid morbidity of extended/extensive surgical approaches.

Keywords: Epithelial ovarian cancer; Cytoreduction; Morbidity; Ovarian cancer; Primary debulking

\section{Introduction}

Epithelial ovarian cancer (EOC) represents nearly $70 \%$ of ovarian cancers and is the second most common cancer among gynecological cancers [1]. EOC is usually diagnosed at the advanced stage (up to $75 \%$ ). Staging surgery is usually enough at the early stage (stages 1-2). However, extended surgical procedures may be needed for advanced stage dis-

Received: 2019.07.05. Revised: 2019.09.04. Accepted: 2019.09.09. Corresponding author: Emre Günakan, MD

Department of Obstetrics and Gynecology, Kecioren Training and Research Hospital, University of Medical Sciences, Pınarbası Mah, Sanatoryum Cad, Ardahan Sok, No:25, Kecioren, Ankara 06380, Turkey

E-mail: emreg43@hotmail.com

https://orcid.org/0000-0001-8854-8190

*Present address of authors: Emre Günakan, Department of Obstetrics and Gynecology, Baskent University School of Medicine, Yukarı Bahçelievler, Mareşal Fevzi Çakmak Caddesi, 10. Sok. No:45, 06490 Çankaya/Ankara, Turkey.

Articles published in Obstet Gynecol Sci are open-access, distributed under the terms of the Creative Commons Attribution Non-Commercial License (http://creativecommons. org/licenses/by-nc/3.0/) which permits unrestricted non-commercial use, distribution, and reproduction in any medium, provided the original work is properly cited.

Copyright $\odot 2020$ Korean Society of Obstetrics and Gynecology 


\section{Obstetrics \& Gynecology Science}

Emre Günakan, et al. Surgical morbidity in ovarian cancer

eases [2]. Aggressive approaches are necessary to achieve maximal cytoreduction but are associated with perioperative and postoperative morbidity and mortality [3]. Surgical extension is associated with intraoperative vascular injury, blood loss, transfusion need, and increased intestinal and urinary tract injury [4].

The extent of surgery, age, comorbidity, and performance status are important predictors for short-term postoperative outcomes [5]. Intraoperative and postoperative complications also extend the hospital stay and delay adjuvant chemotherapy treatment. However, patients may need intensive care after surgery and may die of surgical complications during the early postoperative period. Therefore, the selection of the surgical candidate and preoperative evaluation of risk factors become even more important. In addition, a careful intraoperative evaluation would constitute the basis of follow-up in the healing period.

The objective of our study was to evaluate morbidity of cytoreductive surgery and discuss the risk factors before and after the surgery.

\section{Materials and methods}

Records of all EOC patients, who underwent primary debulking surgery, were evaluated retrospectively. Patients were excluded if they had a history of neoadjuvant chemotherapy. We considered hysterectomy, bilateral salpingo-oophorectomy, bilateral paraaortic and pelvic lymph node dissection, omentectomy, appendectomy, and peritoneal tumor resection as standard surgeries. Extended surgeries included additional bowel resection, splenectomy, pelvic peritonectomy, diaphragm resection, and cholecystectomy. Bowel resection included partial or total colectomy and/or rectum resection. Data from operation notes including intraoperative complications such as haemorrhagia, bowel injury, transfusion, and volume of ascites were recorded. Any injury that required ureter or bladder surgery was considered as a urinary tract injury. Any injury that required ileum, colon, or rectum surgery was considered as a bowel injury. Comorbidities that needed chronic treatment such as hypertension, diabetes, and cardiac failure were considered as chronic diseases. Postoperative complication was defined as a complication that occurred within 30 days after surgery. Patients were considered to be either in the early (stages 1 and 2) or advanced (stages 3 and 4) stages of EOC. The grades of the patients were classified as low (G1 and G2) and high (G3 and clear cell). Lymph node involvement (LNI) was also recorded from the final pathology reports. The threshold values for ascites and cancer antigen 125 (CA125) were $500 \mathrm{~mL}$ and 1,000 IU, respectively. Hospital stay duration, transfusion, postoperative complications such as pleural effusion and ileus, need for intensive care unit (ICU) admission, and chemotherapy start day after surgery were recorded from the database system.

The data were analyzed using SPSS version 15.0 (SPSS Inc., (hicago, IL, USA). Frequency and descriptive analyses were performed. Independent samples $t$-test was used to evaluate the unrelated groups. Chi-square and logistic regression analyses were used to evaluate the factors affecting operative and postoperative complications. A $P$-value $<0.05$ was considered statistically significant.

\section{Results}

A total of 359 patients were included in the study. General characteristics of patients are shown in Table 1. The median age of the study population was $53(21-87)$ years and $68 \%$ of the patients were $<60$ years old. The incidence of serous histology, G3 disease, and advanced stage disease was $73.8 \%, 57.4 \%$, and $69.9 \%$, respectively. Two hundred and forty-eight patients underwent standard surgery and 111 patients underwent extended surgery.

Forty-six intraoperative complications occurred in 42 (11.6\%) patients (Table 2). The most common complications were urinary $(5.2 \%)$, intestinal $(2.8 \%)$, and hemorrhagic (3.9\%) complications. No intraoperative deaths occurred. The need for ICU admission during the postoperative period was $11.7 \%(42 / 359)$.

Factors affecting operative complications were evaluated using multivariate and univariate analyses separately and are shown in Table 3. Multivariate analysis of age, histologic type, LNI, International Federation of Gynecology and Obstetrics (FIGO) stage, presence of ascites, CA125 level, capsule integrity, presence of chronic disease, and extension of surgical approach showed that advanced stage and CA125 level were independently and significantly associated with operative complications (hazard ratio [HR], 1.66; 95\% confidence interval $[\mathrm{Cl}], 1.01-2.73 ; P=0.044$ and $\mathrm{HR}, 1.47 ; 95 \%$ $\mathrm{Cl}, 1.05-2.06 ; P=0.025$, respectively). In univariate analysis, 


\section{Obstetrics \& Gynecology Science}

Vol. 63, No. 1, 2020

Table 1. General properties of patients

\begin{tabular}{|c|c|}
\hline Characteristics & No. (\%) \\
\hline \multicolumn{2}{|l|}{ Age (yr) } \\
\hline$\geq 60$ & 115 (32) \\
\hline$<60$ & $244(68)$ \\
\hline \multicolumn{2}{|l|}{ Histology } \\
\hline Serous & $265(73.8)$ \\
\hline Musinous & $18(5.0)$ \\
\hline Endometrioid & $26(7.2)$ \\
\hline Clear cell & $32(8.9)$ \\
\hline Others & $18(5.0)$ \\
\hline \multicolumn{2}{|l|}{ Grade } \\
\hline 1 & $37(10.3)$ \\
\hline 2 & $84(23.4)$ \\
\hline 3 & $206(57.4)$ \\
\hline Clear cell & $32(8.9)$ \\
\hline \multicolumn{2}{|l|}{ Stage } \\
\hline 1 & $75(20.9)$ \\
\hline 2 & $33(9.2)$ \\
\hline 3 & $203(56.5)$ \\
\hline 4 & $48(13.4)$ \\
\hline \multicolumn{2}{|l|}{ Surgical limit } \\
\hline Standard & $248(69.1)$ \\
\hline Extended & $111(30.9)$ \\
\hline \multicolumn{2}{|l|}{ Surgical complexity score } \\
\hline$<3$ & $12(3.3)$ \\
\hline $4-7$ & $289(80.5)$ \\
\hline$>8$ & $58(16.2)$ \\
\hline \multicolumn{2}{|l|}{ Extended procedures } \\
\hline Splenectomy & $52(14.5)$ \\
\hline Diaphragmatic excision & $18(5.0)$ \\
\hline Pelvic peritonectomy & $60(16.7)$ \\
\hline Colorectal excision & $23(6.4)$ \\
\hline Cholecystectomy & $7(1.9)$ \\
\hline \multicolumn{2}{|l|}{ Ascites $(\mathrm{mL})$} \\
\hline$<500$ & $160(44.6)$ \\
\hline$>500$ & $199(55.4)$ \\
\hline \multicolumn{2}{|l|}{ Intensive care unit } \\
\hline Needed & $42(11.7)$ \\
\hline Not needed & 317 (88.3) \\
\hline
\end{tabular}

Table 2. Complications

\begin{tabular}{|c|c|}
\hline Complications & No. (\%) \\
\hline Intraoperative complications & $\begin{array}{c}\text { (42 patients/ } \\
46 \text { complications) }\end{array}$ \\
\hline Haemorrhagia & $6(1.7)$ \\
\hline Vessel injury & $8(2.2)$ \\
\hline Intestinal injury & $10(2.8)$ \\
\hline Bladder injury & $12(3.3)$ \\
\hline Ureteral injury & $7(1.9)$ \\
\hline Respiratory failure & $2(0.6)$ \\
\hline Obturator nerve injury & $1(0.3)$ \\
\hline Postoperative complications & $\begin{array}{c}\text { (70 patients/ } \\
100 \text { complications) }\end{array}$ \\
\hline Atelectasia & $5(1.4)$ \\
\hline Pleural effusion & $18(5.0)$ \\
\hline Haemorrhagia & $1(0.3)$ \\
\hline Wound infection & $21(6.3)$ \\
\hline Urinary infection & $5(1.4)$ \\
\hline Abscess & $4(1.1)$ \\
\hline Ileus & $21(6.3)$ \\
\hline Intestinal perforation & $3(0.8)$ \\
\hline Hernia & $2(0.6)$ \\
\hline Deep vessel thrombosis & $2(0.6)$ \\
\hline Death & $3(0.8)$ \\
\hline Pneumonia & $3(0.8)$ \\
\hline Cardiac/pulmonary failure & $3(0.8)$ \\
\hline Acute renal failure & $3(0.8)$ \\
\hline Ostomy revision & $1(0.3)$ \\
\hline Trombositopenia & $1(0.3)$ \\
\hline Bile leakage & $1(0.3)$ \\
\hline Evisceration & $2(0.6)$ \\
\hline Sepsis & $1(0.3)$ \\
\hline Late complications & (15 patients) \\
\hline Hernia & $1(0.3)$ \\
\hline Evisceration & $1(0.3)$ \\
\hline Fistula & $1(0.3)$ \\
\hline Deep vessel thrombosis & $2(0.6)$ \\
\hline Ileus & $6(1.7)$ \\
\hline GIS haemorrhagia & $1(0.3)$ \\
\hline Intestinal perforation & $1(0.3)$ \\
\hline Acute renal failure & $1(0.3)$ \\
\hline Death & $1(0.3)$ \\
\hline
\end{tabular}




\section{Obstetrics \& Gynecology Science}

Emre Günakan, et al. Surgical morbidity in ovarian cancer

grade and presence of chronic disease were the only factors without statistical association. The need for ICU admission was also significantly higher in patients with intraoperative complications than in those without intraoperative complications $(28.6 \%$ vs. $8.8 \%, P=0.001)$.

Table 4 summarizes the comparison between morbidity of extended and standard surgeries. Intraoperative and post- operative complication rates were significantly higher for extended surgery than for standard surgery (18.9\% vs. $8.5 \%$, $P=0.005$ and $38.7 \%$ vs. $10.9 \%, P=0.000$, respectively). Intraoperative and postoperative transfusion need, hospital stay, and chemotherapy start day were also significantly higher in extended surgery than in standard surgery.

Hundred postoperative complications occurred in 70 pa-

Table 3. Univariate and multivariate analyses of factors affecting intraoperative complications

\begin{tabular}{|c|c|c|c|c|c|c|c|c|}
\hline \multirow{3}{*}{ Factors } & \multicolumn{5}{|c|}{ Univariate analysis } & \multicolumn{3}{|c|}{ Multivariate analysis } \\
\hline & \multirow{2}{*}{\multicolumn{2}{|c|}{$\begin{array}{c}\text { Complication (+) } \\
\text { No. (\%) }\end{array}$}} & \multirow{2}{*}{\multicolumn{2}{|c|}{$\begin{array}{c}\text { Complication (-) } \\
\text { No. (\%) }\end{array}$}} & \multirow{2}{*}{$P$-value } & \multirow{2}{*}{ HR } & \multirow{2}{*}{$95 \% \mathrm{Cl}$} & \multirow{2}{*}{$P$-value } \\
\hline & & & & & & & & \\
\hline & & & & & & & & \\
\hline$<60$ & 23 & $(9.4)$ & 221 & $(90.6)$ & & & & \\
\hline$\geq 60$ & 19 & $(16.5)$ & 96 & $(83.5)$ & & & & \\
\hline Histology & & & & & 0.008 & & & \\
\hline Serous & 38 & $(14.3)$ & 227 & $(85.7)$ & & & & \\
\hline Others & 4 & (4.3) & 90 & $(95.7)$ & & & & \\
\hline Grade & & & & & 0.117 & & & \\
\hline Low & 19 & $(15.7)$ & 102 & $(84.3)$ & & & & \\
\hline High & 23 & $(9.7)$ & 215 & $(90.3)$ & & & & \\
\hline Stage & & & & & 0.007 & 1.66 & $1.01-2.73$ & 0.044 \\
\hline Early & 5 & $(4.6)$ & 103 & $(95.4)$ & & & & \\
\hline Advanced & 37 & $(14.7)$ & 214 & $(85.3)$ & & & & \\
\hline Lymph node involvement & & & & & 0.005 & & & \\
\hline Present & 29 & $(16.7)$ & 145 & $(83.3)$ & & & & \\
\hline Absent & 13 & $(7.0)$ & 172 & $(93.0)$ & & & & \\
\hline Surgical approach & & & & & 0.007 & & & \\
\hline Standard & 21 & $(8.5)$ & 227 & $(91.5)$ & & & & \\
\hline Extended & 21 & (18.9) & 90 & $(81.1)$ & & & & \\
\hline Ascites (mL) & & & & & 0.013 & & & \\
\hline$<500$ & 11 & (6.9) & 149 & $(93.1)$ & & & & \\
\hline$\geq 500$ & 31 & $(15.6)$ & 168 & $(84.4)$ & & & & \\
\hline CA125 level (IU) & & & & & 0.004 & 1.47 & $1.05-2.06$ & 0.025 \\
\hline$\geq 1,000$ & 21 & (19.8) & 85 & $(80.2)$ & & & & \\
\hline$<1,000$ & 21 & (8.3) & 232 & $(91.7)$ & & & & \\
\hline Capsule integrity & & & & & 0.031 & & & \\
\hline Intact & 4 & $(4.8)$ & 79 & $(95.2)$ & & & & \\
\hline Not intact & 38 & $(13.8)$ & 238 & $(96.2)$ & & & & \\
\hline Chronic disease & & & & & 0.409 & & & \\
\hline Present & 20 & $(13.4)$ & 129 & $(86.6)$ & & & & \\
\hline Absent & 22 & $(10.5)$ & 188 & $(89.5)$ & & & & \\
\hline
\end{tabular}

$\mathrm{HR}$, hazard ratio; Cl, confidence interval; CA125, cancer antigen 125 . 


\title{
Obstetrics \& Gynecology Science
}

\author{
Vol. 63, No. 1, 2020
}

tients. The most frequent complications were ileus (6.3\%), wound infection $(6.3 \%)$, and pleural effusion ( $5 \%)$. Seven $(2.1 \%)$ patients underwent re-operation due to haemorrhagia $(n=1)$, intestinal perforation $(n=3)$, evisceration $(n=2)$, and ostomy revision $(n=1)$. Table 5 presents the factors affecting postoperative complication rates. In multivariate analysis of age, histologic type, histologic grade, LNI, FIGO stage, presence of ascites, CA125 level, capsule integrity, presence of chronic disease, extension of surgical approach, and presence of operative complications, age $(\mathrm{HR}, 1.44 ; 95 \% \mathrm{Cl}$, $1.08-1.93 ; P=0.012)$, extended surgery $(\mathrm{HR}, 1.8 ; 95 \% \mathrm{Cl}$, $1.32-2.44 ; P<0.001)$, presence of ascites $(\mathrm{HR}, 1.63 ; 95 \% \mathrm{Cl}$, $1.13-2.36 ; P=0.008)$, and presence of intraoperative complications ( $\mathrm{HR}, 1.55 ; 95 \% \mathrm{Cl}, 1.07-2.25 ; P=0.019)$ were found to be independently and significantly associated with postoperative complications. In the univariate analysis, the presence of chronic diseases was the only parameter that was not associated with postoperative complications.

The death rate was $0.8 \%$ ( 3 patients). The deaths were caused by cardiopulmonary disorders in 2 patients and sepsis in 1 patient.

\section{Discussion}

EOC is usually diagnosed at the advanced stage and, therefore, requires extensive surgery to minimize the tumor load. In this study, we aimed to report the morbidity of cytoreductive surgery for EOC; our study yielded important findings. Statistical analysis showed that the complication rate was not solely due to surgical extension. Patient factors (such as age), tumor characteristics (such as stage, histology, and grade), and laboratory parameters (such as CA125 level) were also associated with complication rates. Presence of intraoperative or postoperative complications did not negatively affect survival and did not delay the treatment plan. It is worth noting that the significant independent factors were different for intraoperative and postoperative complications. Additionally, the presence of intraoperative complications was associated with the postoperative period. This findings indicates the requirement of appropriate patient selection and patientbased management in the preoperative period.

Most studies on surgical outcomes focus on residual tumor size and long-term effects. The importance of residual tumor size has been well understood, especially over the last 3 decades. Optimal cytoreduction occurs when there are no visible tumors after surgery [6]. The effect of residual tumor size on survival has been emphasized in some studies [7-9]. In a meta-analysis involving 6,885 patients, the optimal debulking rate improvement was $43 \%$ to $66 \%$ [10]. Increased radical approaches are associated with longer survival, but also with higher morbidity. There are similar studies involving stage 3 and 4 patients. Aletti et al. [11] described a surgical complexity system. In their study involving 219 patients, the 3-month mortality rate was $5.9 \%$ and the major morbidity rate was $16.9 \%$. The surgical complexity score (SCS) was associated with 30-day morbidity, and the age and American Society of Anesthesiologists score were associated with both the 30-day morbidity and mortality. In a study involving 28,651 patients, Wright et al. [12] reported that the surgical site and medical complications, transfusion, re-operation, and perioperative mortality rate increased with the number of additional extensive procedures (for additional 0,1 , and $\geq 2$ procedures: $20.4 \%, 34.0 \%$, and $44.0 \%$, respectively). Maximal debulking results in more extensive surgical approaches during treatment for ovarian cancer. Moreover, published

Table 4. Morbidity of surgical extension

\begin{tabular}{lccc}
\hline Factors & Extended surgery & Standard surgery & $\boldsymbol{P}$-value \\
\hline Intraoperative complications & $21(18.9)$ & $21(8.5)$ & 0.005 \\
Postoperative complications & $43(38.7)$ & $27(10.9)$ & $<.0$ \\
Hospital dtay (day) & 14.5 & 15.4 & $<0.001$ \\
Chemotherapy start day (day) & 17.8 & 0.8 & 0.030 \\
Operative blood product need (units) & 3.2 & 3.2 & $<0.001$ \\
Postoperative blood product need (units) & 7.0 & $10(4.0)$ & 0.003 \\
Intensive care unit need & $30(27.0)$ & $<0.001$ & \\
\hline
\end{tabular}

Values are presented as number of patients (\%). 


\section{Obstetrics \& Gynecology Science}

Emre Günakan, et al. Surgical morbidity in ovarian cancer

studies on morbidity after ovarian cancer surgery have been receiving attention over the last decade. In addition, patientbased management is increasingly becoming important.
The postoperative healing period is also important for the start of adjuvant treatment. In a recent study, chemotherapy start day (threshold: 28 days) was associated with the overall

Table 5. Univariate and multivariate analyses of factors affecting post-operative complications

\begin{tabular}{|c|c|c|c|c|c|c|c|c|}
\hline \multirow{3}{*}{ Factors } & \multicolumn{5}{|c|}{ Univariate analysis } & \multicolumn{3}{|c|}{ Multivariate analysis } \\
\hline & \multicolumn{2}{|c|}{ Complication (+) } & \multicolumn{2}{|c|}{ Complication (-) } & \multirow{2}{*}{$P$-value } & \multirow{2}{*}{ HR } & \multirow{2}{*}{$95 \% \mathrm{Cl}$} & \multirow{2}{*}{$P$-value } \\
\hline & No. & $(\%)$ & No. & $(\%)$ & & & & \\
\hline \multicolumn{9}{|l|}{ Age (yr) } \\
\hline$<60$ & 35 & $(14.3)$ & 209 & $(85.7)$ & 0.001 & 1.44 & $1.08-1.93$ & 0.012 \\
\hline$\geq 60$ & 35 & $(30.4)$ & 80 & $(69.6)$ & & & & \\
\hline \multicolumn{9}{|l|}{ Histology } \\
\hline Serous & 63 & $(23.8)$ & 202 & $(76.2)$ & $<0.001$ & & & \\
\hline Others & 7 & $(7.4)$ & 87 & $(92.6)$ & & & & \\
\hline \multicolumn{9}{|l|}{ Grade } \\
\hline Low & 17 & $(14.0)$ & 104 & $(86.0)$ & 0.068 & & & \\
\hline High & 53 & $(22.3)$ & 185 & $(77.7)$ & & & & \\
\hline \multicolumn{9}{|l|}{ Stage } \\
\hline Early & 8 & $(7.4)$ & 100 & $(92.6)$ & $<0.001$ & & & \\
\hline Advanced & 62 & $(24.7)$ & 189 & $(75.3)$ & & & & \\
\hline \multicolumn{9}{|c|}{ Lymph node involvement } \\
\hline Present & 46 & $(26.4)$ & 128 & $(73.6)$ & 0.001 & & & \\
\hline Absent & 24 & $(13.0)$ & 161 & $(87.0)$ & & & & \\
\hline \multicolumn{9}{|c|}{ Surgical approach } \\
\hline Standard & 27 & $(10.9)$ & 221 & $(89.1)$ & $<0.001$ & 180 & $1.32-2.44$ & $<0.001$ \\
\hline Extended & 43 & $(38.7)$ & 68 & $(61.3)$ & & & & \\
\hline \multicolumn{9}{|l|}{ Ascites (mL) } \\
\hline$<500$ & 12 & $(7.5)$ & 148 & $(92.5)$ & $<0.001$ & 1.63 & $1.13-2.36$ & 0.008 \\
\hline$\geq 500$ & 58 & $(29.1)$ & 141 & $(70.9)$ & & & & \\
\hline \multicolumn{9}{|c|}{ CA125 level (IU) } \\
\hline$\geq 1,000$ & 34 & $(32.1)$ & 72 & $(67.9)$ & $<0.001$ & & & \\
\hline$<1,000$ & 36 & $(14.2)$ & 217 & $(85.8)$ & & & & \\
\hline \multicolumn{9}{|c|}{ Capsule integrity } \\
\hline Intact & 4 & $(4.8)$ & 79 & $(95.2)$ & $<0.001$ & & & \\
\hline Not intact & 66 & $(23.9)$ & 210 & $(76.1)$ & & & & \\
\hline \multicolumn{9}{|c|}{ Chronic disease } \\
\hline Present & 33 & $(22.1)$ & 116 & $(77.9)$ & 0.344 & & & \\
\hline Absent & 37 & $(17.6)$ & 173 & $(82.4)$ & & & & \\
\hline \multicolumn{9}{|c|}{ Intra-operative complication(s) } \\
\hline Present & 17 & $(40.5)$ & 25 & $(59.5)$ & 0.001 & 1.55 & $1.07-2.25$ & 0.019 \\
\hline Absent & 53 & $(16.7)$ & 864 & $(83.3)$ & & & & \\
\hline
\end{tabular}

HR, hazard ratio; Cl, confidence interval; CA125, cancer antigen 125. 


\title{
Obstetrics \& Gynecology Science
}

\author{
Vol. 63, No. 1, 2020
}

survival, especially in patients with postoperative residual disease [13]. In our study, the chemotherapy start day was much earlier and clinically very similar in both extended and standard surgery groups (17.8 vs. 15.4 days), even though the difference was statistically significant.

In elderly and poor performance patients, radical approaches may result in higher morbidity. Thus elderly ovarian cancer patients more often undergo non-optimal surgery [14]. Chéreau et al. [15] reported that elderly (29/172 patients $>70$ years) patients underwent less peritoneal and lymphatic excision procedures and had significantly low SCS. In this study, the complication rates were similar. However, the overall survival was worse for the $>70$-year-old group. In a similar study, Fanfani et al. [16] found no difference between the elderly (65-75 years) and very elderly (>75 years) patients. Langstraat et al. [17] reported that age, albumin level $\leq 3 \mathrm{~g} /$ $\mathrm{dL}$, urgent surgery, and stage were associated with poor perioperative outcomes. In this study, the morbidity rate was $37.5 \%$ in $\geq 75$-year-old patients. Wright et al. [12] reported that age was associated with the postoperative complication rate $(<50$ years, $70-79$ years, and $\geq 80$ years: $17.1 \%, 29.7 \%$, and $31.5 \%$, respectively).

Mortality of cytoreductive surgery is also associated with the extension of a surgical approach. Gerestein et al. [18] evaluated 2,434 EOC patients who underwent cytoreductive surgery and the postoperative mortality rate was 3.1\% (76 patients). Forty-seven patients had low SCS $(\leq 3)$. The main causes of death were surgical site infection and pulmonary failure. Age was also associated with the death rate. Aletti et al. [11] reported that SCS is associated with morbidity but not mortality after 3 months. In our study, the mortality rate was nearly $1 \%$, which is consistent with prior studies.

Debulking surgery is the initial step in the management of EOC. As it is the most important postsurgical prognostic factor, the aim of the surgery should be to leave no residual disease. Intraoperative and postoperative complication rates increase with the extensity of the tumor and surgery. Preoperative evaluation of patient performance and expected extension of surgical approach are important during the selection of surgical candidates. Specifically, elderly patients with substantial volume of ascites and/or serious upper abdominal involvement (such as multiple parenchymal infiltration of the liver and spleen or pleural involvement/effusion) should be evaluated comprehensively using a multidisciplinary team approach. Patients may be evaluated after a neoadjuvant che- motherapy in order to decrease the high expected morbidity after primary evaluation. Surgery-associated morbidity and delay of adjuvant treatment can be avoided with good selection. We also suggest that patients who undergo these major surgeries require intensive postoperative care. Therefore, these surgeries should be performed in experienced centers of gynecological oncology.

\section{Conflict of interest}

The authors declare that there are no conflicts of interest, financial or otherwise, related to the material presented herein.

\section{Ethical approval}

Ethical approval for the present study was not required because the study had a retrospective design (Başkent University Review Board a139/2019).

\section{Patient consent}

Written informed consent was obtained from each patient before the surgery.

\section{References}

1. Zhang G, Yao W, Sun T, Liu X, Zhang P, Jin J, et al. Magnetic resonance imaging in categorization of ovarian epithelial cancer and survival analysis with focus on apparent diffusion coefficient value: correlation with Ki-67 expression and serum cancer antigen-125 level. J Ovarian Res 2019;12:59.

2. Timmermans $M$, van der Aa MA, Lalisang RI, Witteveen PO, Van de Vijver KK, Kruitwagen RF, et al. Interval between debulking surgery and adjuvant chemotherapy is associated with overall survival in patients with advanced ovarian cancer. Gynecol Oncol 2018;150:446-50.

3. Kumar A, Janco JM, Mariani A, Bakkum-Gamez JN, Langstraat $C L$, Weaver $A L$, et al. Risk-prediction model of severe postoperative complications after primary de- 


\section{Obstetrics \& Gynecology Science}

Emre Günakan, et al. Surgical morbidity in ovarian cancer

bulking surgery for advanced ovarian cancer. Gynecol Oncol 2016;140:15-21.

4. Aletti GD, Santillan A, Eisenhauer EL, Hu J, Aletti G, Podratz KC, et al. A new frontier for quality of care in gynecologic oncology surgery: multi-institutional assessment of short-term outcomes for ovarian cancer using a risk-adjusted model. Gynecol Oncol 2007;107:99-106.

5. Alphs HH, Zahurak ML, Bristow RE, Díaz-Montes TP. Predictors of surgical outcome and survival among elderly women diagnosed with ovarian and primary peritoneal cancer. Gynecol Oncol 2006;103:1048-53.

6. Stuart GC, Kitchener H, Bacon M, duBois A, Friedlander M, Ledermann J, et al. 2010 Gynecologic Cancer InterGroup (GCIG) consensus statement on clinical trials in ovarian cancer: report from the Fourth Ovarian Cancer Consensus Conference. Int J Gynecol Cancer 2011;21:750-5.

7. Chi DS, Eisenhauer EL, Lang J, Huh J, Haddad L, AbuRustum NR, et al. What is the optimal goal of primary cytoreductive surgery for bulky stage IIIC epithelial ovarian carcinoma (EOC)? Gynecol Oncol 2006;103:559-64.

8. Colombo PE, Mourregot A, Fabbro M, Gutowski M, Saint-Aubert B, Quenet $F$, et al. Aggressive surgical strategies in advanced ovarian cancer: a monocentric study of 203 stage IIIC and IV patients. Eur J Surg Oncol 2009;35:135-43.

9. Harter P, Muallem ZM, Buhrmann C, Lorenz D, Kaub C, Hils $R$, et al. Impact of a structured quality management program on surgical outcome in primary advanced ovarian cancer. Gynecol Oncol 2011;121:615-9.

10. Bristow RE, Tomacruz RS, Armstrong DK, Trimble EL, Montz FJ. Survival effect of maximal cytoreductive surgery for advanced ovarian carcinoma during the platinum era: a meta-analysis. J Clin Oncol 2002;20:124859.
11. Aletti GD, Dowdy SC, Podratz KC, Cliby WA. Relationship among surgical complexity, short-term morbidity, and overall survival in primary surgery for advanced ovarian cancer. Am J Obstet Gynecol 2007;197:676.e17.

12. Wright JD, Lewin SN, Deutsch I, Burke WM, Sun X, Neugut Al, et al. Defining the limits of radical cytoreductive surgery for ovarian cancer. Gynecol Oncol 2011;123:467-73.

13. Hofstetter G, Concin N, Braicu I, Chekerov R, Sehouli J, Cadron I, et al. The time interval from surgery to start of chemotherapy significantly impacts prognosis in patients with advanced serous ovarian carcinoma - analysis of patient data in the prospective OVCAD study. Gynecol Oncol 2013;131:15-20.

14. Cloven NG, Manetta A, Berman ML, Kohler MF, DiSaia PJ. Management of ovarian cancer in patients older than 80 years of age. Gynecol Oncol 1999;73:137-9.

15. Chéreau E, Ballester M, Selle F, Rouzier R, Daraï E. Ovarian cancer in the elderly: impact of surgery on morbidity and survival. Eur J Surg Oncol 2011;37:537-42.

16. Fanfani F, Fagotti A, Salerno MG, Margariti PA, Gagliardi ML, Gallotta $V$, et al. Elderly and very elderly advanced ovarian cancer patients: does the age influence the surgical management? Eur J Surg Oncol 2012;38:1204-10.

17. Langstraat C, Aletti GD, Cliby WA. Morbidity, mortality and overall survival in elderly women undergoing primary surgical debulking for ovarian cancer: a delicate balance requiring individualization. Gynecol Oncol 2011;123:187-91.

18. Gerestein CG, Damhuis RA, de Vries M, Reedijk A, Burger CW, Kooi GS. Causes of postoperative mortality after surgery for ovarian cancer. Eur J Cancer 2009;45:2799803. 